Lavoisier wanted to go deeper.

Here indeed he went astray famously over oxygen, which he named from Greek roots believing it to be the generator of acidity. His etymology came in for some attacks, but much more important was the basis for this name in a generalization from the known acids. First hydrogen sulphide and hydrogen cyanide, and then much more seriously the very strong acid from sea salt, turned out to contain no detectable oxygen when carefully analysed in the absence of water; Humphry Davy in 1810 concluded that they contained none. Oxygen was therefore a misnomer, and the French theory "the baseless fabric of a vision": to accuse the French of calling up cloud-capped towers and gorgeous palaces when they should have been doing sober science was a great pleasure to an Englishman and his listeners in wartime.

All science is open to falsification, and even Lavoisier did not get it all right; but Beretta is critical of Britons in the eighteenth century who saw language in science as a matter of conventions only, and chemistry as essentially a mass of facts. He is very interesting on the different national traditions in Europe in Lavoisier's day, and the way these affected the reception of the new chemistry. In Britain, the language was played down at first, but by 1800 its sheer convenience had prevailed. But perhaps we should note, as Beretta does not, that in medical practice 'antiphlogistic' remedies for reducing fever persisted into the 1820 s, and indeed Davy was given them in his last illness. Priestley, though politically pro-French and, therefore, ending his days as an exile in the United States in 1804, was firmly in favour of the phlogiston theory and nomenclature; but his example does not seem to have kept most English speakers from going along with the French. In Germany, political considerations were more important, and the French armies brought revolutionary principles in politics and chemistry with them.

The book ends with an appendix on alchemical imagery, with the message that this had nothing to do with chemistry. Certainly Beretta's ideal, like Lavoisier's, is a clear language, where analogies rather than metaphors are brought out. But we may feel that something was lost when the language of chemistry became so emphatically prosaic and algebraic, in accordance with Condillac's ideal; Samuel Taylor Coleridge went to Davy's lectures to improve his stock of metaphors, but the language was losing its resonance already. Beretta's book touches on many features of chemistry before 1800 , and is a stimulating addition to the literature.

David Knight is in the Department of Philosophy, University of Durham, Durham $D H 13 H N$, UK

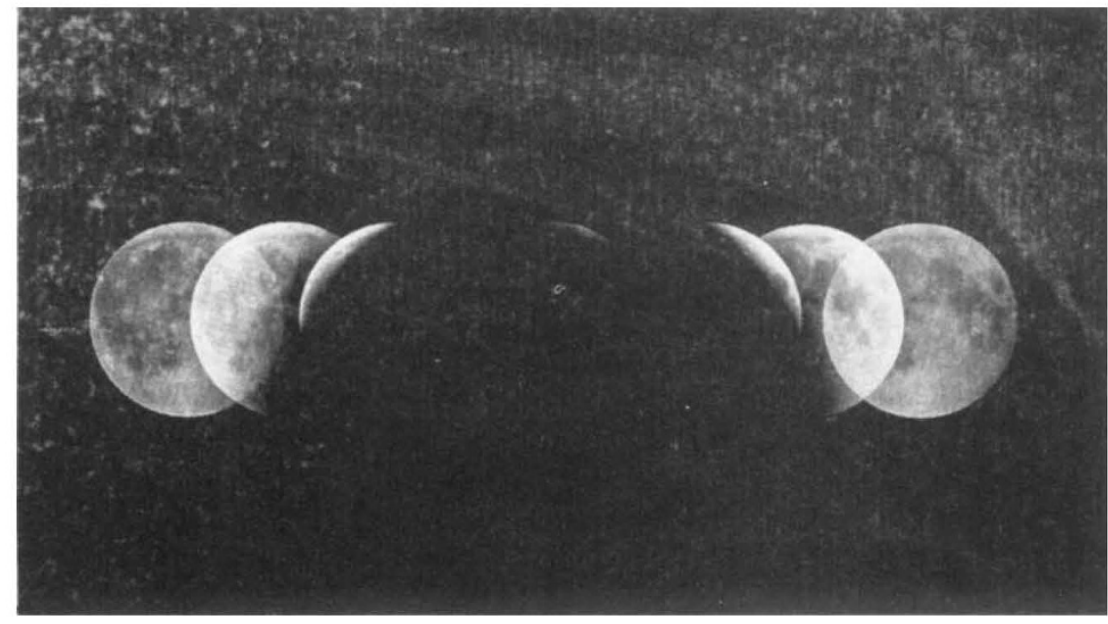

MuLTIPLE exposures of the Moon with the camera tracked at the rate the stars move across the sky reveal the shape of the Earth's shadow. This is one of many examples in a clear and practical guide to eclipse photography, The Cambridge Eclipse Photography Guide: How and Where to Photograph Solar and Lunar Eclipses. Cambridge University Press, £10.95, \$16.95.

\title{
Discovery of the century?
}

Joseph Silk

Wrinkles in Time. By George Smoot and Keay Davidson. Little, Brown: 1993. Pp. 321. £18.99.

Ripples in the Cosmos. By Michael Rowan-Robinson. Freeman: 1993. Pp. 224. £16.99, $\$ 22.45$.

Afterglow of Creation. By Marcus Chown. Arrow: 1993. Pp. 171. £5.99.

RARELY in the modern history of science has there been such a stir as that caused by the Cosmic Background Explorer (COBE) satellite discovery of ripples in the cosmic microwave background radiation. Front-page headlines in newspapers around the world heralded this announcement, accompanied by a picture that, it only later transpired, was mostly instrumental noise. Within hours of seeing the headlines on his way to Narita Airport in Tokyo, John Brockman, the highprofile literary agent, was on a payphone to George Smoot, principal investigator of the Differential Microwave Radiometer (DMR) experiment that mapped the ripples. A book was duly conceived, aided by "the largest deal in the history of science publishing" according to Marcus Chown, and has promptly been written, in collaboration with science journalist Keay Davidson. Wrinkles in Time is the outcome, a somewhat personal series of anecdotes about the vagaries of space astronomy.

What is remarkable about the DMR is that with off-the-shelf (in 1975) technology, Smoot was able to make two major breakthroughs in cosmology. He played a leading role in the group that flew the DMR aboard the U-2 spy plane, to spy on the heavens and discover the motion of our Galaxy relative to the cosmic microwave background radiation. The measured dipole anisotropy provided the first proof that the microwave background was of truly distant origin and likely to be the relic fireball from the Big Bang.

The slight deviation due to our motion was 1 part in 1,000 . Theorists had predicted that at a level of 1 part in 100,000 , one ought to be able to detect the blemishes in the microwave background that represent the seeds of large-scale structure. One sees the primordial fireball radiation when the Universe was only 300,000 years old; it provides a glimpse of the Universe before structure had formed. However, this increase in sensitivity required a space-borne platform, and Smoot nurtured the DMR experiment into a reincarnation on board the COBE satellite. The satellite was originally destined for the Space Shuttle, but the Challenger disaster made necessary a redesign and the experiment had to be reduced to fit into a Delta rocket that was launched four years ago. Fifteen years had elapsed since NASA's decision to proceed with COBE.

The wait was worthwhile. The farinfrared absolute spectrometer (FIRAS) carried on COBE, designed by John Mather, measured the most precise fit to a Planck function ever performed on a black body in the sky. The cosmic microwave background radiation is so perfect a black body that it could have originated only in the fiery furnace of the first months of the Big Bang. The DMR also performed according to plan. It mapped the entire sky at a resolution of 7 degrees, and measured slight deviations from uniform- 
ity in the microwave background. The discovery of fluctuations, at the expected level of 1 part in 100,000 , meant that the Big Bang was finally a respectable and consistent theory: the last remaining enigma was solved.

The vagaries of space astronomy are also the subject of Ripples in the Cosmos by Michael Rowan-Robinson. The author is professor of astrophysics at Imperial College, London, and has written several popular books on astronomy. He played an important role in the Infrared Astronomical Satellite (IRAS), an infrared space telescope built by a team from the United States, United Kingdom and the Netherlands and launched in 1983. IRAS provided the first all-sky map at infrared wavelengths, and revolutionized our perspective on the cosmos. The most luminous galaxy in the Universe was first seen as an IRAS source. Only in the infrared can one penetrate the cores of interstellar dark clouds, where stars are conceived and born. Only in the infrared can one get an accurate all-sky tally of the large-scale galaxy distribution. This map was used to provide a measure of where in the Universe the gravitational acceleration originates that accounts for the motion of our Galaxy as reflected in the dipole anisotropy in the microwave background. Rowan-Robinson includes a chapter that describes the impact on his life of the ripple announcement.

For the real dirt on COBE, however, I recommend Marcus Chown's slender tome, Afterglow of Creation. The science editor of New Scientist brings a journalistic fervour to delve into the personalities behind the headlines. Here you will read random quotations by the key players about the many rivalries between scientists striving for their share of glory. Both Chown and Rowan-Robinson take care to give proper credit to Arno Penzias and Robert Wilson for accidentally discovering, while employed by Bell Laboratories as young radioastronomers, the microwave background radiation. Chown describes the discovery of the microwave background and the COBE announcement of the ripples, peppered with speculations about Nobel prizes, and why scientists, when stumbling for appropriate words, inevitably need to invoke God for an appropriate metaphor. The public was bombarded with deistic analogies in the post-COBE euphoria, including seeing "the face of God", the "handwriting of God", and discovering the "Holy Grail", not to mention the more secular tribute of "the discovery of the century, if not of all time". Most of the scientists who quoted these words to the media soon came to regret their moment of passion, as a backlash inevitably developed. However, now that the DMR ripples have been confirmed, there is little doubt that the discovery of the cos- mic microwave background fluctuations, as well as the unprecedented precise measurement of its black body spectrum, are a major breakthrough in our understanding of the cosmos. We can reasonably anticipate that appropriate recognition will be made when the attention of the Nobel committee refocuses on astrophysics in a few years' time.

Joseph Silk is in the Astronomy and Physics Departments and Center for Particle Astrophysics, University of California, Berkeley, California 94720, USA.

\section{Physically impossible}

\section{David Goodstein}

Fear of Physics: A Guide for the Perplexed. By Lawrence M. Krauss. Basic Books: 1993. Pp. 206. \$20. (To be published in the UK by Jonathan Cape in 1994 at £17.99).

WHAT we have here is nothing less than an attempt to do the impossible. Fear of Physics, with an apology in the preface to Erica Jong, is subtitled $A$ Guide for the Perplexed, Moses Maimonides unattributed. I'm sure Erica could have taught Maimonides a thing or two, but that's not what this book is about. This is definitely Maimonides, gently introducing Erica to the wisdom of the ages, meaning, of course, contemporary theoretical physics.

Lawrence Krauss, of Case Western Reserve University, has undertaken to explain it all in simple language, almost without committing a single equation. In less than 200 pages, he covers just about everything. Scales, dimensions, little numbers and big numbers and the usefulness of scientific notation; from Galileo to Gell-Mann, from dark matter to critical point fluctuations to the Higgs boson condensate; it's all here (I didn't notice anything on the fractional quantum Hall effect, but I may have dozed off for a few pages). Every bit is explained in clean, simple prose. There is barely a paragraph anywhere that could have been made easier to understand. And yet, sad to say, the enterprise as a whole doesn't quite succeed.

Part of the reason has to do with Krauss. His accounts of physics are technically excellent, but he tends to be sloppy about anything less important to him than physics itself. For example, in one place we are told that Johannes Kepler was Tycho Brahe's student. At a different level of intellectual sloppiness, we are told at another point that Albert Einstein was the Columbus of the twentieth century (you know, the world is round, and spacetime is curved). Another problem is that Krauss feels obliged to intersperse amusing anecdotes in his text, but he has no flair at all for telling them. He chooses the oldest chestnuts around, then delivers them poorly. That includes the one about the theoretical physicist's contribution to dairy farming, the spherical cow. He immediately admits that it's not funny, although he makes it the central metaphor of the book (there's a picture of a cow on the dust jacket - let's hope Erica doesn't misunderstand). I've heard the joke many times and, depending on the skill of the storyteller, sometimes it is funny.

These are quibbles. The real problem is the impossibility of the task itself. Krauss explains point A to us; he can't explain it to us the way he would to an undergraduate class, much less to his own colleagues, because that is not the nature of the undertaking. Instead he surrounds it with metaphors, analogies, simplified examples and so on. When he's done, because he does it very well, we have a pretty good idea of why physicists think point $\mathrm{A}$ is so important, and we may even think we've grasped the point itself.

The problem comes when he starts to explain point $B$, which requires that we already understand point $\mathrm{A}$. He uses all the same strategies just as nicely as before, but now we realize that point $A$ was more slippery than we thought, and point B is really shaky. Then it's on to point $\mathrm{C}$. By the time we get through the entire alphabet pretty much all is lost, except to the unperplexed who had no fear of physics in the first place.

By ironic coincidence, I read Krauss's explanation of the importance of the Superconducting Super Collider on the very day that it died ("Congress finally drove a wooden stake through its heart", said the New York Times). Some day, when history sorts out all these things, it may be decided that the era that ended that day failed for the same reason Krauss's book did. We physicists left the public 300 years behind. The gap has turned out to be too big to fill in.

Richard Feynman, who is one of Krauss's heroes, once had a similar failure. He tried to teach physics to a class of bright first-year college students. $\mathrm{He}$ ended up instead leaving us a set of books that are useless to students but are nevertheless enduring classics of the scientific literature. Fear of Physics is not in that category, but (aside from my quibbles) it is beautifully written and painless to read. Somewhere on the spectrum of scientific sophistication, there must be an audience for this book. I hope the book and the audience find one another.

David Goodstein is in the Department of Physics, California Institute of Technology, Pasadena, California 91125, USA. 